\title{
Clinics of Oblivion: Makeover Culture and Cosmetic Surgery
}

\section{Tourism}

\author{
Meredith Jones, University of Technology, Sydney ${ }^{1}$
}

If you want gorgeous breasts and a 5 star holiday, but are on a budget, then we have the answer for you. (http://www.gorgeousgetaways.com

[t]he quest for authenticity is a declining force in tourist motivation. (Rojek 1997: 71)

\section{Introduction}

Data drawn upon in this paper comes from a pilot study conducted in mid-2009 (funded by the University of Technology, Sydney), which examined Australians seeking cosmetic surgery in Thailand, a country whose cities, beaches and islands have long been popular destinations for Australian holiday-makers. The cosmetic surgery tourists I interviewed had purchased their operations in packages that included airfares, transfers, hospital and hotel accommodation, surgery and anaesthetic costs. Some of them had also arranged sightseeing and cultural tours, and one had booked a private nurse. For most of them, the overall cost was approximately a third of the price of their surgery alone at home. Nine Australian residents participated, all were interviewed in Australia prior to travel, five were interviewed whilst in Bangkok seeking surgery at the Yanhee Hospital and eight were re-interviewed upon return to Australia. All names have been changed. One participant chose not to continue with the project after the first interview.

\footnotetext{
${ }^{1}$ The author is recipient of a UK Economic and Social Research Council funded international grant, 'Sun, Sea, Sand and Silicone: Aesthetic Surgery Tourism,' with David Bell, Ruth Holliday, Elspeth Probyn and Jacqueline Sanchez-Taylor, running from 2011 to 2013 (http://www.genderstudies.leeds.ac.uk/research/cosmetic-cultures/aesthetic-surgery-tourism.php).
}

PORTAL Journal of Multidisciplinary International Studies, vol. 8, no. 2, July 2011. Health and Borders Across Time and Cultures: China, India and the Indian Ocean Region Special Issue, guest edited by Beatriz Carrillo García and Devleena Ghosh. ISSN: 1449-2490; http://epress.lib.uts.edu.au/ojs/index.php/portal PORTAL is published under the auspices of UTSePress, Sydney, Australia. 
Participants were sourced via a cosmetic surgery tourism consultant in Sydney who had an ongoing contract with Yanhee hospital (the roles of these consultants will be the subject of further papers). Yanhee is a suburban hospital known by locals as the 'Beauty Hospital.' It is not as glamorous or as central as the famous Bumrungrad or Bangkok hospitals, and unlike them its foyers do not resemble a five-star hotel (however, it is famous for its rollerblading assistants, as discussed below). All the participants were staying at the same hotel in Nonthaburi, near the hospital, and all except one had brought family or friends with them. Interviews were carried out at the hospital and in the hotel.

\section{Consuming place, beauty and status}

Hot Promotion. Breast Implants. Free Hotel 10 Nights. Complete Package. (http://www.cosmedicjetaways.com/)

Although statistics are unreliable, Thailand is probably the country with the most medical tourists in Asia, if not the world. John Connell writes that 'Thailand is the contemporary global centre of medical tourism' (2011: 76, see also Wilson 2011: 121). The country promotes 'wellness tourism' (yoga, aromatherapy, spa treatments) and is known mainly for its cosmetic surgery, gender reassignment and dental procedures (Cook 2010; Whittaker 2008). Thailand markets itself as the 'land of smiles' and many websites emphasize its tropical climate and the gracious hospitality of its people: 'have high standard cosmetic procedures in a relaxed atmosphere, where you can make your recovery while enjoying famous Thai hospitality, the scenery, excellent hotels and fabulous restaurants, which will make you feel like you are in your own island paradise' (http://www.jungceylonclinic.com/).

Importantly, in Thailand medical tourism is embraced at the highest governmental levels: 'Thai government and business articulate their investment in medical tourism in terms of economic nationalism' (Wilson 2011: 126). More than half of the revenue of Bumrungrad International hospital in Bangkok is generated from international patients (Kittikanya 2007), more than one million foreigners overall seek treatment in Thailand annually, and cosmetic surgery tourism is the most popular of all the medical tourisms in Thailand (Wilson 2011: 123-124). ${ }^{2}$

\footnotetext{
${ }^{2}$ A view prevails that it is rich Westerners who seek cosmetic surgery tourism. However, in 2006 Japanese formed the largest foreign group using the services of Thai hospitals (Wilson 2011:124). Andrea
} 
All tourist destinations, including those involved in cosmetic surgery tourism, offer both actual and imagined specialties and services: 'particular places trade on certain images (or maybe myths) in order to "sell" themselves' (Bell et al. 2011: 4). Thus there are certain ideas about Thailand that people bring to bear when choosing it as a cosmetic surgery tourism destination. One of these is apparent in a fascinating article by Aren Aizura about differences between Thai and non-Thai transwomen seeking gender reassignment surgery in Thailand. Aizura writes that there is a 'circulation of feminine beauty as a standard-bearer for Thai nationalism, and as emblematic of Thai governmental aspirations to modernity and status as a developed nation' (2009: 305). This understanding of Thailand as a place where a certain kind of femininity can be embraced, performed and created meant, for the transwomen Aizura interviewed, that the country was experienced 'not only as the site of their reassignment surgeries, but as a geocultural space that enabled them to supplement their own sense of psychic feminisation' (2009: 308).

A Thai version of feminine beauty was also important for the cisgendered women I interviewed. ${ }^{3}$ Marion, travelling with her husband and two sons from Brisbane, was having an abdominoplasty ('tummy tuck') operation. She told me:

We were in Siam Paragon and I wanted bathers, and they only had up to size 12. And the girl at the counter yelled really loud, "Extra large! Extra large!" sort of pointing at me [laughing], cos they had them out the back and that's what they thought I needed. And I'm not even big by Australian standards, at home I'm just a normal 12 or small 14! But you know they're all so tiny.

I asked her how she felt being treated by and cared for by Thai women who generally have small, delicate frames. She replied, laughing,

Yeah and they don't age either! Like I asked [international liaison officer at the hospital] what she'd had done and she said nothing! Imagine I could look like her, although I know I never can, but maybe [I will] take some of that back with me. I think I will. It's all experience, part of the experience, and that's Thailand. The people are beautiful, really friendly like they mean it. Honestly I've been treated so great by them, like a Queen. Maybe [because they're beautiful] that's why they're so good at cosmetic surgery.

For Marion, the delicate beauty of Thai women seemed to be part of the commodity she was purchasing. By having her surgery in a place known for a certain kind of femininity,

Whittaker also shows that many Thai transnationals seek medical care 'at home' using medical services designed for tourists (2009).

3 'Cisgender' is a term designed to complement 'transgender.' It refers to individuals whose birth-gender, bodies, sexualities and identities are, socially and culturally, comfortably aligned. It replaces 'gendernormative,' which suggests a normal/abnormal dichotomy. 
she thought she could possibly acquire some of that herself: 'maybe [I will] take some of that back with me.'

Being made to feel 'like a queen' was another important part of Marion's experience and most interviewees made similar observations. As Wilson points out, 'While many of the medical tourists from Europe or North America profiled in the media are hardly elites in their own countries, they are elite in a global sense' (2011: 125). All of the interviewees talked about the luxurious yet cheap (by Australian standards) hotel, the attentiveness of the staff and the seemingly 'genuine' care they were receiving, and many referred to themselves as privileged in one way or another. On walking into Yanhee, Josie, who had travelled with her sister from Melbourne for breast implants and a rhinoplasty, told me:

You know when you walk in and it's so crowded, and there's all those desks? God I was freaking out just then, just like aaaaah! like what've I got myself into and where do I go but then I found the international desk and from there it was just wham wham wham [clicks her fingers], into the lift, meet my personal assistant for the day, do you want a coffee, do you want a tea, here's the menu, anything you want, fresh juice, smoothies, everything. Like I was a celebrity!

Josie, a dental hygienist, and Marion, a chef's assistant, felt they were being treated like royalty or celebrity, and this change of status was a key part of the cosmetic surgery tourism experience for them. Clearly then, the experience of having cosmetic surgery overseas happens on many levels in addition to those directly connected to the surgery. Cosmetic surgery itself is a way to 'move up' in the world, gaining status by acquiring beauty and/or youthfulness and often, in turn, self-confidence. The self-improvement that cosmetic surgery promises is foreshadowed and enhanced for cosmetic surgery tourists in Thailand and many other destinations because, for a brief time in a foreign land, they are part of a privileged class: they are rich, elite and pampered.

\section{Cosmetic surgery and makeover culture}

Cosmetic surgery worldwide has risen astonishingly in the last decade. Once a rare indulgence for the rich or narcissistic it is now part of mainstream beauty and grooming practices and is, for many, an aesthetic and cultural imperative (Heyes \& Jones 2009; Jones 2008; Pitts 2007). The cosmetic surgery industry is predicted to be worth US $\$ 40$ billion globally by 2013, rising from an estimated US\$31.7 billion in 2008 (Elder 2009). Cosmetic surgery recipients were once seen as patients: their desires were pathologized and consequently those seeking cosmetic surgery were often secretive and ashamed 
(Spitzack 1988). However, cosmetic surgery has gradually become a consumable item: its recipients are no longer 'patients' but rather 'clients' whose surgeries occur in a new global conglomeration of media, technological and aesthetic conditions. Thus cosmetic surgery is far more than a medical or surgical practice: it occurs at and highlights the intersection of tremendously complex and significant social trends concerning the body, gender, psyche, medical practice and ethics, globalization, aesthetic ideologies, and both communication and medical technologies. ${ }^{4}$

Makeover culture is a term I have used to describe the set of cultural logics in which cosmetic surgery is embedded (Jones 2008). Importantly, makeover culture does not just apply to cosmetic surgery: it can be used to describe a broad set of cultural, social and aesthetic changes. While I argue that cosmetic surgery is both symptom - and one of the causes - of makeover culture, the term can also be applied to a much wider spectrum of current cultural concerns and desires. Put very simply, my broad argument has been that makeover culture encourages a state where becoming something better is more desirable than being that improved thing. Makeover culture concentrates more on the process of development than on the idea of completion. The idea of the self not as a fixed entity but as a construct to be worked upon is not a new one of course, but the difference that I assert is that in order to be a good citizen of makeover culture requires demonstrable, performative transformation of the self. We may certainly choose what we want to transform into, and how we would like to do it, but transformation itself is not elective and nor is it ever finished. Self-improvement is something that in makeover culture everyone needs, and it is a continuing enterprise. In this way the key point of cosmetic surgery is not to reach some point of physical perfection, but instead to display the self as a work-in-progress: to show and to feel that one is becoming, and developing.

Two decades ago cosmetic surgery recipients spoke about choosing surgery in order to become 'whole' or 'normal' (Davis 1995). Now they are more likely to see cosmetic surgery as a product or a purchase (Jones \& Heyes 2009), and to narrate it as part of a grooming or fashion regime rather than a pathway to the true self. Cosmetic surgery is one of the few medical procedures linked to fashion as well as to health and it has become a status symbol in some cultures (Jones 2012).

\footnotetext{
${ }^{4}$ For example, the seemingly closed relationship between surgeon and patient is actually one dependent upon and part of assemblages of media, physical location, support industries, and global economics (Jones 2008: 59-81).
} 


\section{Medical tourism}

Medical tourism is also growing rapidly. It was estimated in 2006 to be worth US\$513 billion globally (Carrera et al. 2006: 448) and is forecast to rise to US $\$ 100$ billion by 2012 (Herrick 2007). Revenues for Asia alone could be US\$4.4 billion by 2012 (Murphy 2007). There are many complex issues connected with contemporary medical tourism (see Connell 2011 for a comprehensive overview). Far from resulting from a set of decisions that occur only at the individual level, medical tourism has been instituted at the highest echelons. Indeed, the case of healthcare has been linked to the two founding principles of the European Union: freedom of movement of goods and freedom of movement of services (Pennings 2007: 505). This means that on an institutional, state, and global level, healthcare is now a tradeable commodity as well as a public service.

With some important recent exceptions (Aizura 2009; Whittaker 2009; Cook 2010; Connell 2011; Holliday \& Elfving-Hwang forthcoming) most writing about medical tourism still concentrates on categorization and definition: sociologist Peta Cook writes that "the limited studies on medical and health tourism ... tend to focus on a business perspective, and often seek to understand and limit the phenomenon to static, universal definitions' (2010: 136; see also Connell 2011: 15). Nevertheless, if we do wish to taxonomize medical tourism then Cook offers some useful tools, arguing that medical tourism is made up of travel that a) seeks medical treatment for pre-existing health conditions; b) consists of moving beyond home borders, and c) seeks out traditional tourism experiences, secondary to medical treatments (2010: 140).

Interestingly, Cook's last category rules out some who would otherwise be labeled medical tourists. Andrea Whittaker argues that people who seek medical treatment abroad but do not combine it with tourist experiences are more usefully called 'medical travelers' (Cook 2009; see also Kangas 2010, and Bell et al. 2011). And indeed, one of the women I interviewed was adamant that her planned trip for facelift surgery in Bangkok was not tourism:

Look. I'm not going there for fun, not, no way for that. Cost is the, for me, the reason. And quality, high quality of the treatment there. Dr - has emailed me and he's got my photos and I just want to get there, I'll just go there and do it. No, it's not a holiday, not a holiday. How could it be, I'll be on painkillers, I'll be wrapped up like a mummy (Carmela). 
This response was given in a rather offended tone, and Carmela refused any further interviews. When I saw her in a lift at the hotel (and she was heavily bandaged) she ignored me. I never saw her by the pool or in the restaurant—it seemed she had confined herself to her room, to taxis, and to the hospital. She was not seeking out tourist experiences and was in fact trying to avoid them. This indicates that in further research it will be essential to examine differences between medical travel and medical tourism, as Whittaker advises.

Equity and access are two dilemmas of medical tourism. Arguments proliferate both for and against cross-border healthcare. It is seen by some as indicative of failures of states to provide for their citizens: 'medical tourism can be seen as a symptom signalling the flaws of the system' (Pennings 2007: 506) while others list benefits for sender-countries like reduction in waiting lists and less pressure on health systems. There may also be advantages for receiver-countries as medical tourism adds to export revenue. It may lead to development of high-level healthcare clinics and technologies (Mattoo \& Rathindran 2006), although working to ensure that local residents have access to such facilities is another matter (Bookman \& Bookman 2007: 169-185). Health professionals may receive better training if their countries engage in medical tourism. However, it is more likely that countries undertaking the practice will do so at a cost to their own citizens (Pennings 2007: 507). Many are now 'exporting' healthcare services despite providing low levels of healthcare for their general populations, as foreign nationals jet in to partake of procedures and treatments that residents could never afford: 'The term 'medical tourism' especially refers to the flows of citizens from countries with industrial, post-industrial, or oil wealth to medical sites in less developed countries, themselves often sites of international tourism, such as Costa Rica, Brazil, or Thailand' (Wilson 2011: 122). At its worst, medical tourism could seriously undermine the healthcare systems of developing countries, taking medical professionals and resources away from providing basic care for residents.

\section{Cosmetic surgery tourism}

Cosmetic surgery tourism is the hybrid child of both medical tourism and cosmetic surgery. From charlatans who organize illegal operations and offer no follow up care, to companies that fly overseas surgeons into Australia to conduct consultations in airport hotels (Duff \& Hall 2007), to highly respected international hospitals offering first class 
medical services connected to luxurious holidays, the area is undergoing rapid development. Cosmetic surgery tourism shares the same issues as medical tourism in general while also posing its own complex variations on moral, ethical and social issues.

There does exist work on cosmetic surgery in different national contexts, especially China (Brownell 2005), South Korea (Woo 2004; Holliday \& Elfving-Hwang forthcoming) and Brazil (Edmonds 2007 \& 2010). Marketing companies are carefully mapping and predicting the growth of cosmetic surgery tourism and there are popular journalistic (Kuczynski 2006) and fictocritical pieces (Morgan 2009) available. However, there is little work on this topic from a sociological, ethnographic or cultural studies point of view (Heyes \& Jones 2009; Connell 2006 \& 2011) with some notable exceptions (Holliday \& Elfving-Hwang forthcoming). I suggest that because contemporary cosmetic surgery, as outlined earlier, is part of makeover culture - in particular ideas about self-love, body-maintenance, and self-transformation - it is more easily coupled with holidays and luxury than, say, a hip replacement operation might be. In this context then, perhaps travelling to Thailand for a five-star holiday and a facelift is, in our global and media-saturated world, a logical consumer choice.

\section{Stripper boobs and rollerskating girls}

Cosmetic surgery tourism works at global, national and local levels, but also at the most personal and physical levels: the minutiae of an eye-fold or the intimacy of a nipple. Vera Mackie and Carolyn Stevens suggest that the sites at which global processes play out are 'local, interpersonal, intimate and, most specifically, embodied' (2009: 257), and they point out that these more intimate sites have been largely ignored in the study of globalization. Similarly, Ara Wilson insists that it is both 'bodily and economic transformations that characterize the internationalization of medical care through medical tourism' and, further, that 'medical tourism is both a media-saturated construct and a set of institutional practices' (Wilson 2011: 122). We can see this complex interplay between the mediatized, the institutional, the global and the corporeallyintimate in the following narrative:

On the $23^{\text {rd }}$ floor, high above the Chao Phraya River in Nonthaburi, an outlying district of Bangkok, I sit in the cool air-conditioning of Carrie's hotel suite. We are drinking bourbon and coke. If we walk out onto the balcony and into the humidity we can see far 
below us two major streams of lights - cars on vast highways - curling through the blackness. Carrie sits down, gingerly, holding her torso steady. She had breast implants put in yesterday morning and is now wearing a constriction garment. I wonder to myself whether she would be consuming alcohol so soon after an operation if she were in Australia. Her husband Daniel is with her, and her mother-in-law Betty. Betty has come to help with Carrie and Daniel's toddler, Jayne, who keeps grabbing the television remote control and trying to press the buttons, gurgling and screaming with delight. We all keep laughing at her.

I first met Carrie and Daniel at their small beachside home on the north coast of New South Wales. Carrie had decided to have breast implants and wanted to have them done in Thailand, where it was cheaper and the family could join her on a holiday afterwards. Daniel had been shocked and upset at first — he told me he was frightened about infection and side effects, and scared that Carrie would end up with what he called 'stripper boobs' - but he hadn't shared these concerns with her and was intent on supporting her decision. Now, here they are in Thailand, the operation is over, and the mood in their suite is one of lightness, relief, and some excitement.

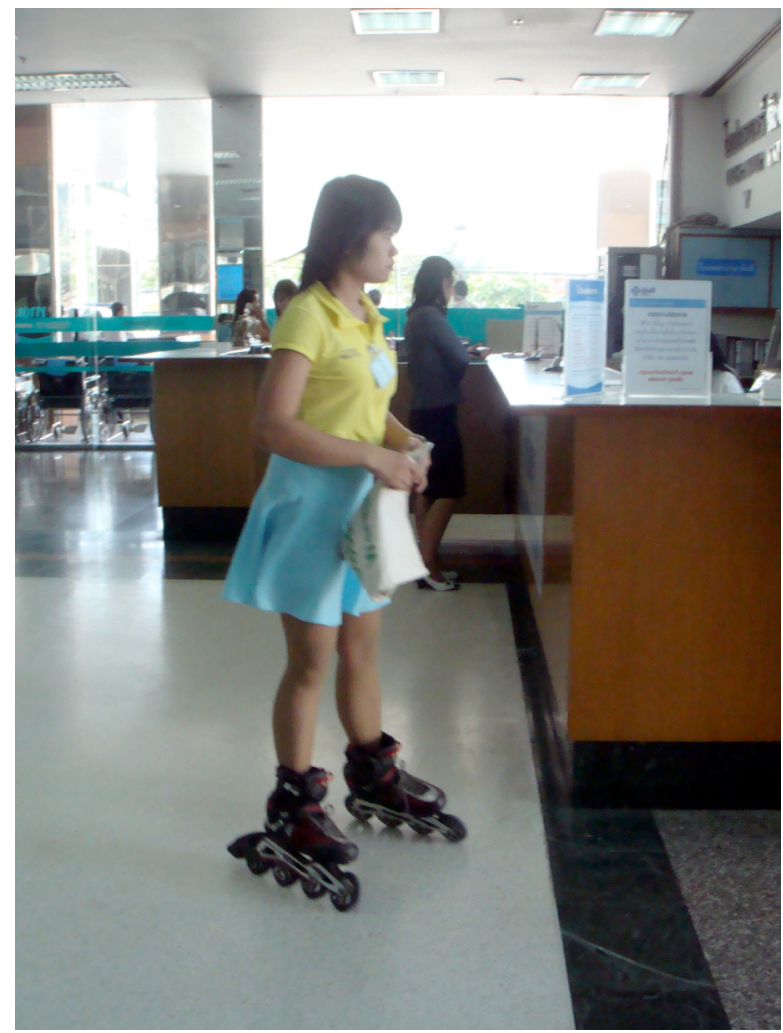

Rollerblading Assistants at Yanhee (C) Meredith Jones. 
I ask Carrie how it all went, and she takes a deep breath:

Carrie-yeah, yeah, really good. It was surprising when you walk in, it's just nurses and desks and people everywhere. And then the rollerblading girls that go past [laughing]. So yeah, pretty surreal, nothing like we have at home. But it was beautiful, real clean, even the private hospitals at home aren't that, they're not like that.

Daniel — they've got a pretty fast turn around, I mean you were in there for just under twenty four hours.

Carrie-yeah and when you look at all the people who were in the waiting room, just for the cosmetic surgery area, there would have been at least seventy people just for cosmetic surgery. Yeah, just really really surreal, looking in, and having the rollerblade girls going past!

Daniel-we saw that years ago on Ripley's Believe It or Not, and then all of a sudden we saw it and we're like 'oh, gee, this is the hospital!'

Daniel is excited and keeps on interrupting Carrie with facts and figures like 'the doctor said that the infection rate was 0.004 , and from the last six months out of five thousand operations for breast augmentations they've got zero percent. So it certainly beats the Royal North Shore Hospital.' This is borne out by John Connell's research into medical tourism: "in the larger cities the "best" hospitals and their skilled health workers are comparable, and are accredited as such, with the best global standards' $(2011: 10){ }^{5}$

A crucial part of Carrie's decision to have the surgery overseas was being able to include her family. As Connell says, 'though queries can be raised over whether patients can be designated as tourists, their companions can usually be seen as such' (2011: 11). The financial aspects are compelling-Carrie took her husband, her mother-in-law and her toddler with her, they spent a week in the hotel, then a week in a resort at Phuket, and the entire cost was AU\$8000. In Australia Carrie would have paid AU\$10-12,000 for the surgery alone. Clearly, while a major motivation for having cosmetic surgery offshore is financial, there is far more to explore. Carrie's story also informs us about interactions between the global and the local, the importance of the notion of place, and the (too easy to forget) utterly intimate corporeal nature of cosmetic surgery tourism. Transformation and rejuvenation — notions deep at the heart of cosmetic surgery - are also, vitally, parts of travel and tourism. To examine this connection between cosmetic

\footnotetext{
${ }^{5}$ Marketing directed at UK residents sometimes highlights 'the "third world" National Health Service, promising much higher standards of care than are available at home' (Bell et al. 2011: 4), and may also draw upon a kind of 'medical nostalgia' for a higher, more personal level of health care that was (at least mythically) available in tourist's home countries (Bell et al. 2011: 8).
} 
surgery and tourism I bring together sociologist Chris Rojek's work on contemporary tourism with my own work on makeover culture.

\section{Makeover culture and clinics of oblivion}

I originally took the word makeover from contemporary popular culture where it increasingly signifies a range of activities or lifestyle practices including home renovation, interior decorating, gardening, urban renewal, food preparation, and even business invigoration. But the term can also, of course, be applied to tourism. Indeed, many of the characteristics of makeover culture resonate with Rojek's work on contemporary tourism, especially those outlined in his important article 'Indexing, Dragging and the Social Construction of Tourist Sights' (1997).

Rojek argues that we bring meaning to tourist sites via processes of 'indexing' and 'dragging.' 'Indexing' is a way of taxonomizing the various aspects of a tourist site as it is known to us. These aspects may be wide ranging. When considering New York, for example, a tourist's index might include televisual memories of the twin towers falling, as well as scenes from Sex and the City, and all sorts of other understandings of Manhattan gleaned from movies, books, and travel agents. Crucially, Rojek reminds us, indexing takes into account both 'factual and fictional elements ... and operates on conscious and unconscious levels' (1997: 53).

Towards the end of the interview I ask Carrie if she has any regrets and she replies 'no, no, well the only thing I regret is that I've sort of taken up two days of my holidays, [laughter all around] but we'll make up for it, we're going to the MBK building tonight, have you been there, it's amazing isn't it?' In a previous interview in Australia she had told me:

\footnotetext{
We're going on a few tours over there, a safari tour, I think three days after the operation, so I'm hoping it will be alright, they say it should be ok as long as I take the pain killers. And the next day, we're going on the Bridge Over the River Kwai tour, markets and boat rides, and then on to a resort later that week. I looked online, it looks beautiful, it's got its own proper beach, two different pools, stuff for my daughter to do, elephants and lions and things like that.
}

So what Carrie brought to her experience as a cosmetic surgery tourist had been gleaned from films (The Bridge on the River Kwai), television (Ripley's Believe It or Not) and a notion of the ideal resort holiday, while Daniel brought to the experience an understanding of cosmetic surgery gleaned from the bodies of strippers. 
Carrie and Daniel were indexing in their plans for their trip to Thailand, bringing to bear fact (statistics about the hospital) and fiction (their interest in the film Bridge Over the River Kwai) as well as hopes and fears about the surgical results. Hand in hand with indexing, 'dragging' is the process by which indexed elements from fiction and fact, from conscious and unconscious ways of 'knowing a place' are brought to the tourist experience. Dragging helps us to create a 'collage' in relation to place that may include the experience of actually being there as just one of many elements. Given this, Rojek asks, 'if sights are always potpourris which utilize elements from a variety of index files at both conscious and unconscious levels, how can one speak of an authentic experience of the real place?' (1997: 55).

The idea of authenticity is important. Rojek notes and examines a change in tourism, in line with changes due to globalization, where authenticity is perceived as something not inherent in a place but rather stitched together from various fictional, factual and sensorial elements. Authenticity is therefore something created by the user rather than a pre-existing element in certain sites. The idea parallels makeover culture, in which subjects actively construct their own bodies, value ongoing self-creation, and seek out meaning via the development and collage of the self rather than via a process of searching for the 'authentic.'

Cosmetic surgery tourism combines makeover culture and the 'collage tourism' that Rojek describes. It is both imaginative and corporeal. Cosmetic surgery recipients undergo a process of imagining a body and/or face that is suitable, beautiful, desirable and ideal. They construct this from many sources: personal, historical, media, celebrity, etc. But crucially, the only way that the 'ideal' body and/or face can be actualized is at the corporeal level. Cosmetic surgery cannot happen by remote control or in virtuality. Thus the 'indexing' of cosmetic surgery brings together the fantasy of physical beauty with the reality of what scalpels, surgeons and lasers can actually do. Like 'collage tourism,' cosmetic surgery demands a balance between fact and fiction, ideal and real, imagined and corporeal.

Cosmetic surgery requires spaces where transformation can occur. These may be mediaspaces (such as the 'blank' between before and after photographs), physical spaces like the clinic or operating theatre, or psychic and emotional spaces in which the 'new' body is imagined. Often, such spaces are invisibilized or elided because they 
contain painful and messy elements of transformation. But what happens when one of these spaces is the space of the holiday? What happens when we come out of anaesthesia and emerge not into our normal lives but into a resort, a safari, or a yoga workshop? I suggest that the holiday is an ideal space for transformation to occur. Within a tourist experience the transformation of the body/face is cushioned and framed by other (spiritual, cultural, emotional) transformations of the self. So, incongruous as having surgery while abroad may seem, in this context it makes perfect sense- the cosmetic surgery in cosmetic surgery tourism is only one of the changes the tourist undergoes, only one element in a suite of transformative experiences facilitated by indexing and dragging: 'The beach, the hotel, the casino, the ocean, the mountains and a variety of other tourist motifs are presented in the advertising materials almost as clinics of oblivion where we can check-in and then check-out from the cares of everyday life' (Rojek 1997: 58, my italics). In other work I have argued that in makeover culture there is an important period apart, a time of transformation separated from the rest of everyday life (Jones 2008). This break from normal life in order to undergo transformation is epitomized in makeover programs like Extreme Makeover and The Swan, that actually remove participants for periods of months, placing them in bootcamp worlds where mirrors are forbidden, food and exercise are highly regulated, and contact with friends and family extremely limited. These psychic and physical 'breaks' in time and space correspond with the 'clinics of oblivion' that Rojek identifies in contemporary tourism, and his use of the word 'clinic' is very interesting as it implies a place where transformation occurs.

Further, whereas traditional tourism is about external actions such as gazing outwards at sights, cosmetic surgery tourism (and all medical tourism) is about the traveller's own body. In terms of tourist sites, I argue that the cosmetic surgery recipient's own body is the site to be 'discovered' and experienced. And this is not confined to cosmetic surgery tourism: many people bring home corporeal souvenirs of their travels: a tan, a tattoo, a scar, a piercing (one of the women I interviewed and her partner had matching tattoos inked on their arms while in Thailand, and another had her navel pierced). This is another established expression of tourism that cosmetic surgery tourism fits into. In this schema the body becomes a landscape 'travelled to' and it then becomes the souvenir to be brought home. 
Before concluding I want to flag some of the ways that cosmetic surgery tourism differs from other medical tourisms. Strikingly, all but one of the women I interviewed chose to have extra surgery at the last minute (sometimes while already in their theatre gowns). These procedures ranged from a chin implant to laser resurfacing to scar revision to Botox injections (which they all had). To my surprise most of the partners - husbands, sisters, mothers-in-law - also chose, while in Thailand and after spending time at the hospital, to have something done: this was mostly teeth whitening and Botox injections, although one husband had root canal surgery. In traditional medical tourism the patient is highly unlikely to have other surgeries on the spur of the moment. Thus cosmetic surgery tourism might be aligned with an overseas shopping tour where impulse buying is encouraged, and where purchases are not tee-shirts and snow domes but bodily transformations.

Another difference between medical tourism and cosmetic surgery tourism may lie in the ways in which experiences are narrated afterwards:

Carrie-I couldn't really fault it, the only thing I could, if I had to pick something that was to complain about ... is how I had to wait when I first got there. And it was only about an hour and a half.

Daniel—no, you said you were a bit upset that they didn't give you a pre-op or a sedation to calm you down.

Carrie [laughing] - yeah they forgot to give me the pre op. But it was good apart from no pre-op, oh, that was terrible, they put the heart measure thing on me and it was like dododododododopumping cause I'm just panicking — but the nurse was coming over and saying 'it's alright, you'll be alright.' It's funny now that I think about it but at the time it's the worst thing that can happen, the worst thing they can do, oh it's so funny.

Carrie had been awake being wheeled into theatre, awake as her arms were being tied down, fully conscious until moments before the first incision. She had had operations before and knew she should have been given a pre-op. She was the only one of the nine women I interviewed who had surgery at Yanhee who had this experience - all the others had received pre-op injections. Such an oversight or mistake could, of course, be made in any hospital, and I have no intention of using this incident to argue that cosmetic surgery tourism is any more dangerous than cosmetic surgery at home. But I suggest that this anomaly, in any context other than of cosmetic surgery tourism, including other medical tourism, may well have been seen in an entirely different light. As it was, Carrie relayed the incident as if it were part of an adventure - a scary thing that happened as part of her wonderful holiday, something that was frightening at the 
time but in hindsight added to the excitement and the atmosphere. Only one day after the operation the experience was already taking on the qualities of a holiday story told to friends - the lack of a pre-op was being aligned with the pickpocketed wallet, the lost luggage, and the seasickness on the way to the Greek island.

Drawing on this I suggest that people who have cosmetic surgery overseas are more likely to positively narrativize - and perhaps even trivialize - the medical experience than those who have their surgeries at home. Claudette, who had travelled with her boyfriend from Sydney's Northern Beaches, told me of having her breast implants headbutted by a giraffe as she walked on a platform at a wildlife park and nearly vomiting with the pain. Marion told me, laughing, of bouncing around in a tuk-tuk and feeling like her abdominoplasty stitches were about to pop. Thus, in further research into cosmetic surgery tourism, it will be important to observe what stories tourists tell as well as how they tell them.

\section{Conclusion}

Velocity is finally more important as a priority of tourism than arriving. (Rojek 1997: 71)

Contemporary tourist experiences are absolutely in line with cosmetic surgery experiences. Both come about via mediated and pedagogical relationships with cultural sites, be they tourist destinations or the bodies of the ideal and beautiful. Cosmetic surgery and tourism are conceptually connected and their joining in the form of cosmetic surgery tourism makes perfect sense. Mackie and Stevens assert that mobility itself is, in the era of globalization, 'a potent symbol of personal power' (2009: 257). I suggest that in cosmetic surgery tourism, as in makeover culture, ideas of mobility, velocity, and becoming are more important than arrival or stasis.

In makeover culture there is no 'authentic': no point at which the self or the body is complete or replete. There are only ongoing self-improvements, additions and fragmentary enhancements to the collage that makes up the subject. When we partake in cosmetic surgery tourism our bodies themselves are 'touched' and altered forever by the experience. This is a most intimate form of tourism, where what we bring home are often profoundly altered bodies as well as new or rejuvenated selves (so long as everything goes to plan). 
While the medical tourism industry may be 'fueled and driven by patients who feel disenfranchized by the healthcare system in their own country' (Horowitz et al. 2007: 37) cosmetic surgery tourism is different because of its association with other less practical - but nonetheless powerful - drivers such as glamour, international notions of beauty, and global media. It is remarkable in the context of an international 'makeover culture' that marries consumer practices and values with new attitudes towards beauty, ageing and grooming (Elliott 2008; Jones 2008; Covino 2004). Bodies have always, in some way, been brought into being via the technologies by which they travel and are viewed, adjusted, augmented and understood. Thus it is logical to posit medical tourism and cosmetic surgery as technologies that, together, form a particular body: the body of the cosmetic surgery tourist.

\section{Acknowledgements}

I would like to sincerely thank the two peer reviewers who offered generous insight and advice, Beatriz Carrillo García for her patience, and Emily Hunter for her careful editing.

\section{Reference List}

Aizura, A. Z. 2009, 'Where Health and Beauty Meet: Femininity and Racialisation in Thai Cosmetic Surgery Clinics,' Asian Studies Review, vol. 33, no. 3: 303-317.

Bell, D., Holliday, R. Jones, M., Probyn, E., \& Sanchez Taylor, J. 2011, 'Bikinis and Bandages: An Itinerary for Cosmetic Surgery Tourism,' Tourist Studies, 1468797611416607, first published on August 1, 2011 as doi:10.1177/1468797611416607.

Bookman, M. Z. \& Bookman, K. R. 2007, Medical Tourism in Developing Countries. Palgrave Macmillan, New York.

Brownell, S. 2005, 'China Reconstructs: Cosmetic Surgery and Nationalism in the Reform Era,' in Asian Medicine and Globalization, (ed.) J. Alter. University of Pennsylvania Press, Philadelphia: 132150.

Carrera, P., Bridges, M. \& John, F. P. 2006, 'Globalization and Healthcare: Understanding Health and Medical Tourism,' Pharmacoeconomics and Outcomes Research, vol. 6, no. 4: 447-454.

Connell, J. 2006, 'Medical Tourism: Sea, Sun, Sand and ... Surgery,' Tourism Management, vol. 27 , no. 6: 1093-1100. 2011, Medical Tourism, CABI, Wallingford, Oxfordshire.

Cook, P. 2010, 'Constructions and Experiences of Authenticity in Medical Tourism: The Performances of Places, Spaces, Practices, Objects and Bodies’ Tourist Studies, vol. 10, no. 2: 135-153.

Cosmetic Jetaways website. Online, available: http://www.cosmedicjetaways.com/ [accessed 12 August 2011].

Covino, D. C. 2004, Amending the Abject Body: Aesthetic Makeovers in Medicine and Culture, State University of New York Press, Albany.

Davis, K. 1995, Reshaping the Female Body: The Dilemma of Cosmetic Surgery, Routledge, New York.

Duff, E. \& Hall, L. 2007, 'The Ugly Facts Behind Beauty Tourism Boom,' Sydney Morning Herald, 30 September. Online, available: http:/www.smh.com.au/news/national/the-ugly-facts-behind-beautytourism-boom/2007/09/29/1190486633685.html [accessed 2 July 2008].

Edmonds, A. 2007, “"The Poor Have the Right to be Beautiful”: Cosmetic Surgery in Neoliberal Brazil,' Journal of the Royal Anthropological Institute (N.S.), vol. 13: 363-381. 
2010, Pretty Modern: Beauty, Sex, and Plastic Surgery in Brazil. Duke University Press, Durham,

NC, New York \& London.

Elder, M. 2009, Cosmetic Surgery Markets: Products and Services, BCC Research, summary. Online, available: http://www.bccresearch.com/report/HLC061A.html [accessed 12 August 2011].

Elliott, A. 2008, Making The Cut: How Cosmetic Surgery Is Transforming Our Lives, University Of Chicago Press, Chicago.

Gorgeous Getaways website. Online, available: http://www.gorgeousgetaways.com [accessed 12 August 2011].

Herrick, D. M. 2007, Medical Tourism: Global Competition in Health Care, NCPA Policy Report no. 304, National Center for Policy Analysis, Texas, USA. Online, available: http://www.ncpa.org/pub/st304?pg=3 [accessed 12 August 2011].

Heyes, C. \& Jones, M. (eds) 2009, Cosmetic Surgery: A Feminist Primer, Ashgate, London.

Holliday, R. \& Elfving-Hwang, J. (forthcoming), 'Gender, Globalisation and Aesthetic Surgery in South Korea,' Body \& Society (earlier version: Online, available: http://leeds.academia.edu/RuthHolliday/Papers/744838/Gender_Globilization_and_Cosmetic_Surg ey_in_South_Korea)[accessed 12 August 2011].

Horowitz, M. Rosensweig. J. 2007, 'Medical Tourism: Globalization of the Healthcare Marketplace,' Medscape General Medicine, vol. 9, no. 4: 33-42.

Jones, M. 2008, Skintight: An Anatomy of Cosmetic Surgery, Berg, Oxford. (2012, forthcoming) 'Cosmetic Surgery and the Fashionable Face,' Journal of Fashion Theory, Special Issue: BodyParts: Cataloguing the Dressed Body, vol. 16, no. 1.

Jungceylon Plastic Surgery Clinic website. Online, available: http://www.jungceylonclinic.com/ [accessed 12 August 2011].

Kangas, B. 2010, 'Travelling for Medical Care in a Global World, Medical Anthropology, Vol. 29, no. 4: 344-362.

Kittikanys, C. 2004, 'Health,' Bangkok Post Economic Year End Review 2004. Online, available: http://www.bangkokpost.com/midyear2004/health02.html [accessed 29 July 2011].

Kuczynski, A. 2006, Beauty Junkies: Inside our \$15 Billion Obsession with Cosmetic Surgery, Doubleday, New York.

Mackie, V. \& Stevens, C. 2009, 'Globalisation and Body Politics,' Asian Studies Review, vol. 33, no. 3: 257-273.

Mattoo, A. \& Rathindran, R. 2006, 'How Health Insurance Inhibits Trade in Health Care,' Health Affairs, vol. 25 , no. 2: 358-368.

Morgan, K. P. 2009, 'Women and the Knife: Cosmetic Surgery and the Colonization of Women's Bodies,' in Cosmetic Surgery: A Feminist Primer, (eds) C. Heyes \& M. Jones. Ashgate, London \& New York: 49-77.

Murphy. C. 2007, 'The Globalization of Surgical Care: The Implications of the Rise of Medical Tourism for the United States,' Boston College Student Bioethics Research Journal. Online, available: http://www.bc.edu/clubs/mendel/ethos/archives/2007/murphy.shtml [accessed 2 June 2008].

Pitts, V. 2007, Surgery Junkies: Wellness and Pathology in Cosmetic Culture, Rutgers University Press, New York.

Rojek, C. 'Indexing, Dragging and the Social Construction of Tourist Sights,' in Touring Cultures: Transformations of Travel and Theory, (eds) C. Rojek \& J. Urry. Routledge, London \& New York: 52-74.

Spitzack, C. 1988, 'The Confession Mirror: Plastic Images for Surgery,' Canadian Journal of Political and Social Theory, vol. 12, nos. 1-2: 38-50.

Whittaker, A. 2008, 'Pleasure and Pain: Medical Travel in Asia,' Global Public Health: An Interdisciplinary Journal for Research, Policy and Practice, vol. 33: 271-290. 2009, 'Global Technologies and Transnational Reproduction in Thailand,' Asian Studies Review, vol. 33, no. 3: 319-332.

Wilson, A. 2011, 'Foreign Bodies and National Scales: Medical Tourism in Thailand,' Body \& Society, vol. 17, nos. 2-3: 121-137.

Woo, K. J. 2004, 'The Beauty Complex and the Cosmetic Surgery Industry,' Korea Journal, vol. 44, no. 2: 52-82. 